Rev. Elet. em Gestão, Educação e Tecnologia Ambiental (e-ISSN: 2236-1170)

\title{
QUALIDADE SANITÁRIA DE SEMENTES DE AVEIA-PRETA CV. COMUM SUBMETIDOS A DIFERENTES TRATAMENTOS
}

\section{QUALITY HEALTH SEED OATS-BLACK CV. COMMON SUBJECT TO DIFFERENT TREATMENTS}

\author{
Marciele Barbieri ${ }^{1}$, Viviane Schons de Ávila², Marciéli Pitorini Bovolini ${ }^{3}$, Marlove Fátima Brião \\ Muniz ${ }^{4}$, Andréa Cristina Dörr ${ }^{5}$ \\ ${ }^{1}$ Universidade Federal de Santa Maria (UFSM) - Aluna do curso de Agronomia. E-mail: marcieleb@ymail.com \\ ${ }^{2}$ UFSM - Aluna do curso de Agronomia: vivi_31589@hotmail.com \\ ${ }^{3}$ UFSM - Aluna do curso de Engenharia Florestal: m.bovolini@hotmail.com \\ ${ }^{4}$ UFSM - Eng. Agrônoma, Profa. Adjunta do Departamento de Defesa Fitossanitária: marlovemuniz@yahoo.com.br \\ ${ }^{5}$ UFSM - Profa. Adjunto do Departamento de Ciências Econômicas: andreadoerr@yahoo.com.br
}

http://dx.doi.org/10.5902/223611708800

\section{RESUMO}

O trabalho objetivou estudar os efeitos de diferentes tratamentos na sanidade de sementes de aveia preta comum (Avena strigosa SCHREB). As sementes foram submetidas aos seguintes tratamentos: Vincit 50 SC, Vincit $50 \mathrm{SC}+$ Trichodel $^{\circ}$, Trichodel ${ }^{\oplus}$; Testemunha sem tratamento, após ficaram acondicionadas em caixas do tipo gerbox, com substrato papel-filtro umedecido em água destilada e esterilizada. Permaneceram em câmaras B.O.D. na temperatura de $25 \circ \mathrm{C}$, com fotoperíodo de 12 horas, até a avaliação. Os fungos associados às sementes foram identificados com o auxilio de microscópio estereoscópico e óptico, após sete dias de incubação. O delineamento estatístico utilizado foi inteiramente casualizado com quatro tratamentos e oito repetições de 50 sementes cada. Os fungos Alternaria spp, Fusarium spp., Botrytis spp., Rhizoctonia spp., Phoma spp. e Trichoderma spp. foram identificados em Avena strigosa. Os resultados mostraram que o produto químico (Vincit 50SC), isolado ou associado com Trichodel ', foi eficaz para o controle de fungos potencialmente patogênico para as sementes de aveia preta. Palavras-chave: fungos, Trichodel, Vincit $50 \mathrm{SC}$

\begin{abstract}
The study investigated the effects of different treatments on seed health of black oat (Avena strigosa SCHREB). Seeds were subjected to the following treatments: witness, Vincit ${ }^{\circledR} 50$ SC, Trichodel ${ }^{\circledR}+$ Vincit $^{\oplus} 50$ SC, Trichodel ${ }^{\circledR}$, control without treatment after they were packed in boxes gerbox substrate filter paper moistened with sterile distilled water. BOD remained in chambers at $25 \circ \mathrm{C}$, with a photoperiod of 12 hours until the evaluation. The seedborne fungi were identified with the aid of a stereoscopic microscope and optical after seven days of incubation. The statistical design was completely randomized with four treatments and eight replicates of 50 seeds each. The fungus Alternaria spp, Fusarium spp. Botrytis spp. Rhizoctonia spp. Phoma spp. and Trichoderma spp. were identified in Avena strigosa.Os results showed that the chemical (Vincit ${ }^{\circledR}$ 50SC), isolated or associated with Trichodel ${ }^{\circledR}$ was effective for the control of potentially pathogenic fungi for oat seeds.
\end{abstract}

Keywords: fungi, Trichodel ${ }^{\circledast}$, Vincit 50 SC 


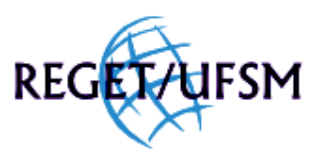

BARBIERI et all , v(11), no 11, p. 2413-2418, JUN, 2013.

Rev. Elet. em Gestão, Educação e Tecnologia Ambiental (e-ISSN: 2236-1170)

\section{INTRODUÇÃO}

A aveia preta é uma gramínea pertencente à família das Poaceae, utilizada como planta forrageira e também para a produção de grãos. Segundo Bevilaqua e Pierobom (1995), essa forrageira de inverno, juntamente com o azevém, apresenta grande importância econômica.

A relevância dos patógenos associados às sementes foi citada em trabalho realizado por Soave e Wetzel (1987) que alguns fungos patogênicos transmitidos pelas sementes são economicamente importantes, pois constituem fontes de inóculo para o desenvolvimento de doenças e podem interferir na emergência e estabelecimento das culturas. Segundo Harman et al. (2000), Trichoderma possui influência sobre o crescimento das plantas, e também há evidências da indução de resistência localizada e sistêmica por espécies de Trichoderma, em algumas plantas, para vários patógenos. Além disso, Barbosa et al. (2001) descrevem como características enzimas de degradação, como, celulases, quitinases e pectinases, as quais encontram-se envolvidas no processo de controle biológico.

O vigor das sementes afeta diretamente a emergência das plântulas e o estabelecimento das culturas no campo, podendo gerar perdas na produção. Estes aspectos de desempenho incluem a taxa e uniformidade de germinação de sementes e crescimento de plântulas em laboratório (SCHUCH et al., 1999), emergência e crescimento de plântulas no campo (SCHUCH E LIN, 1982; SCHUCH, 1999), habilidade de emergência de plântulas em condições ambientais desfavoráveis, além de afetar o crescimento e rendimento da planta.

Conforme Balardin e Lock (1987), o tratamento de sementes consiste em uma alternativa concisa e econômica que garante maiores percentuais de germinação e emergência das plântulas, isto é resultante do retardamento da infecção primária das sementes e, redução de inóculo de patógenos radiculares e de solo. Ainda existem, além dos fungicidas químicos, produtos bioprotetores que surgiram no intuito de reduzir a utilização de pesticidas sintéticos, os riscos aos operadores e os possíveis prejuízos ao meio ambiente.

Os testes empregados para a determinação da qualidade fisiológica das sementes são os de germinação e vigor, dentre estes se destaca o teste de envelhecimento acelerado, que foi desenvolvido para avaliar o vigor de sementes, tentando estimar o potencial de armazenamento das sementes principalmente em relação à umidade e temperaturas elevadas. Baseia-se no princípio, de acordo com Marcos Filho et al. (1987), se aumentar a temperatura e a umidade elevam-se a taxa de deterioração das sementes, sendo a deterioração variável de acordo com o seu vigor inicial.

Para a melhoria da qualidade fisiológica e sanitária das sementes de cereais de inverno, o emprego de fungicidas eficientes tem por objetivo principal reduzir, a baixos níveis, a taxa de transmissão dos patógenos, visando secundariamente, a elevação da emergência (FORCELINI, 1995). 


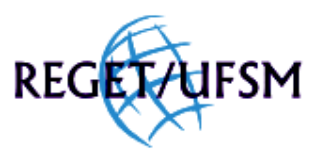

BARBIERI et all , v(11), no 11, p. 2413-2418, JUN, 2013.

Rev. Elet. em Gestão, Educação e Tecnologia Ambiental (e-ISSN: 2236-1170)

O objetivo proposto a este trabalho consisti em avaliar o efeito dos tratamentos biológico e químico, isolados e em associação, na qualidade sanitária das sementes de aveia- preta cv. comum.

\section{METODOLOGIA}

As sementes de aveia-preta cv. comum (Avena strigosa) foram procedentes do município de Júlio de Castilhos-RS, e foram obtidas através de um produtor local. Após a recepção, as sementes foram submetidas ao teste de sanidade desenvolvidos no Laboratório de Fitopatologia do Departamento de Defesa Fitossanitária da Universidade Federal de Santa Maria.

Os testes de sanidade foram realizados utilizando oito repetições de 50 sementes. As sementes foram submetidas a quatro tipos de tratamentos: T1 (Testemunha sem tratamento), T2 (Vincit 50 SC), T3 (Vincit 50 SC + Trichodel ${ }^{\circledR}$ ) e T4 (Trichodel ${ }^{\circledR}$ ); após, as mesmas foram colocadas em caixas acrílicas transparentes (gerbox) com dimensões de 11 × $11 \times 3 \mathrm{~cm}$, previamente desinfestadas com solução de hipoclorito de sódio (1\%) e álcool (70\%). Utilizaram-se como substrato duas folhas de papel-filtro, umedecidas com água destilada esterilizada. A verificação da ocorrência de fungos foi feita com auxílio de microscópio estereoscópico, onde as sementes foram observadas individualmente. A identificação dos fungos em nível de gênero foi realizada com microscópio óptico e literatura disponível (BARNETT e HUNTER,1999).

O delineamento experimental utilizado foi o inteiramente casualizado. As médias foram comparadas pelo Teste de Tukey a 5\% de probabilidade, no programa estatístico Sisvar 5.3 (FERREIRA, 2008).

\section{RESULTADOS E DISCUSSÕES}

Os fungos Alternaria spp., Fusarium spp., Phoma spp., Botrytis spp. e Rhizoctonia spp., foram identificados em sementes da variedade aveia-preta comum (Tabela 1). A incidência de 79,5\% de Alternaria spp. para o tratamento testemunha destacou-se em relação aos demais fungos identificados nas sementes. Bevilaqua e Pierobom (1995) descrevem a ocorrência de Alternaria spp., Bipolaris spp. e F.graminearum em aveia preta. Segundo os mesmos autores, além dos fungos patogênicos, foram encontrados fungos de armazenamento associados às sementes de aveia-preta. Também foram detectados aqueles causadores de helmintosporiose (Helmintosporium spp), com influência direta na germinação das sementes e no desenvolvimento das plantas.

Para as sementes tratadas com o produto químico Vincit $50 \mathrm{SC}$ e as associadas com produto químico Vincit $50 \mathrm{SC}$ em conjunto com produto biológico Trichodel, verificou-se a baixa incidência de Alternaria spp., Botrytis spp. e Phoma spp.. Dessa forma pode-se concluir que a associação dos produtos foi eficaz para a redução destes fungos. Em estudos realizados por Souza 


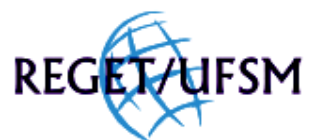

BARBIERI et all , v(11), no 11, p. 2413-2418, JUN, 2013.

Rev. Elet. em Gestão, Educação e Tecnologia Ambiental (e-ISSN: 2236-1170)

et al. (2009), o tratamento das sementes de aveia preta com fungicida possibilitou longos períodos de condicionamento para a classificação de lotes de semente, sem levá-los à ausência da germinação, quando comparado com o processo sem tratamento com fungicida.

Já quando foi utilizado somente Vincit $50 \mathrm{SC}$ no tratamento das sementes, pode-se notar a eficiência do mesmo para o controle de Phoma spp.. O uso do fungicida não interferiu no desenvolvimento do gênero Trichoderma spp. associado as sementes de aveia preta, sugerindo que o produto químico e biológico podem ser utilizados complementarmente (Tabela 1).

Ao analisar a eficiência do tratamento com o produto biológico Trichodel ${ }^{\circledR}$, constatou-se que não houve presença de Fusarium spp. e Botrytis spp., considerados fungos patogênicos para algumas espécies agrícolas. Segundo Maciel et al. (2009) avaliando a sanidade das sementes de aveia preta submetidas a termoterapia, os fungos que ocorreram com mais freqüência foram Aspergilus spp. (32\%) e Phytophora spp. (3.5\%). Martins-Corder e Melo (1997), constataram que Trichoderma spp. como agente de controle biológico proporciona a elevação na germinação de sementes, na emergência e vigor de plântulas de berinjela.

A maior percentagem de Trichoderma spp. (34,75\%) relacionado com todos os tratamentos realizados, manifestou-se no tratamento do produto químico Vincit $50 \mathrm{SC}$ com o produto biológico Trichodel ${ }^{\circledR}$, mostrando assim, que este tratamento poderá ser uma boa alternativa de controle dos fungos patogênicos de sementes. Segundo Corrêa (2009), os microrganismos, Trichoderma, Clonostachys, Bacillus e Pseudomonas são associados à promoção de crescimento de plantas. Para Faria et al. (2003), sementes de algodão quando foram submetidas ao tratamento com $T$. harzianum, carboxin+thiram e carbendazin+thiram apresentaram estatisticamente percentagem de germinação superior à testemunha.

Tabela 1. Fungos associados a sementes de aveia preta cv. Comum com diferentes tratamentos. Santa Maria, 2012

Gêneros fúngicos (\%)

Tratamentos

Altemaria spp. Fusarium spp. Rhizoctonia spp. Botrytisspp. Phoma spp. Trichoderma spp.

\begin{tabular}{ccccccc} 
Testemunha & $79,5 \mathrm{a}^{*}$ & $5,25 \mathrm{ab}$ & $3,5 \mathrm{~b}$ & $10,75 \mathrm{a}$ & $23,0 \mathrm{a}$ & $0 \mathrm{c}$ \\
Vincit 50SC & $1,75 \mathrm{c}$ & $8,5 \mathrm{a}$ & $7,5 \mathrm{ab}$ & $10,5 \mathrm{a}$ & $0 \mathrm{~b}$ & $10,5 \mathrm{bc}$ \\
$\begin{array}{c}\text { Vincit 50SC+Trichodel } \\
\text { Trichodel }\end{array}$ & $4,5 \mathrm{c}$ & $0,25 \mathrm{~b}$ & $24,0 \mathrm{a}$ & $0 \mathrm{~b}$ & $1,0 \mathrm{~b}$ & $34,75 \mathrm{a}$ \\
\hline C.V.(\%) & $32,25 \mathrm{~b}$ & $0 \mathrm{~b}$ & $12,75 \mathrm{ab}$ & $0 \mathrm{~b}$ & $3,0 \mathrm{~b}$ & $25,25 \mathrm{ab}$ \\
\hline
\end{tabular}




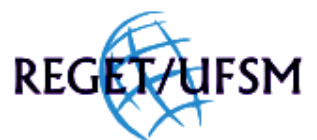

BARBIERI et all , v(11), no 11, p. 2413-2418, JUN, 2013.

Rev. Elet. em Gestão, Educação e Tecnologia Ambiental (e-ISSN: 2236-1170)

*Médias seguidas pela mesma letra na coluna, não diferem entre si pelo teste de Tukey aos $5 \%$ de probabilidade.

\section{CONCLUSÕES}

Os fungos identificados nas sementes de aveia preta foram: Alternaria spp., Fusarium spp., Rhizoctonia spp., Botrytis spp., Phoma spp. e Trichoderma spp. O fungicida Vincit ${ }^{\circledR} 50$ SC, isolado ou associado com Trichodel é promissor para o controle dos fitopatógenos associados às sementes de aveia-preta.

\section{REFERÊNCIAS BIBLIOGRÁFICAS}

BALARDIN, R. S.; LOCH, L. C. Efeito de thiram sobre a germinação de sementes de centeio e aveia. Revista Brasileira de Sementes, v. 9, n. 1, p. 113-117, 1987.

BARBOSA, M.A.G. et al. Antagonism of Trichoderma species on Cladosporum herbarum and their enzymatic characterization. Brazilian Journal of Microbiology, v. 32, p. 98-104, 2001.

BARNETT, H. L.; HUNTER, B. B. Illustred genera of imperfect fungi. 3 Ed. Minnesota: Burgess Publishing Company, 1999. $241 \mathrm{p}$.

BEVILAQUA, G. A.; PIEROBOM, C. R. Qualidade sanitária e fisiológica de sementes de aveia-preta (Avena strigosaSchreb) da zona sul do Rio Grande do Sul. Revista Brasileira de Sementes, v. 17, n. 1, p. 19-22, 1995.

CORRÊA, E. B.; BETTIOL, W. Controle Biológico da Podridão de Raízes Causada por Pythium spp. em Cultivos Hidropônicos. Jaguariúna: Embrapa Meio Ambiente, 2009. 26 p.

FARIA, A. Y. K.; ALBUQUERQUE, M. C. F.; NETO, D. C. Qualidade fisiológica de sementes de algodoeiro submetidas a tratamentos químico e biológico. Revista Brasileira de Sementes, v. 25, n. 1, p. 121-127, 2003.

FERREIRA, D. F. SISVAR: um programa para análises estatísticas e ensino de estatística. Revista Symposium, v. 6, p. 36$41,2008$.

FORCELINI, C. A. Tratamento de sementes de trigo no Brasil. In: MENTEN, J. O. M. Patógenos em sementes: detecção, danos e controle químico. São Paulo: Ciba Agro, 1995. p. 247-264.

HARMAN, G. E. Myth and dogmas of biocontrol changes in perceptions derived from research on Trichoderma harzianum T-22. Plant Disease, v. 84, n. 4, p. 377-393, 2000.

MARCOS FILHO, J.; CÍCERO, S. M.; SILVA, W. R. Avaliação da qualidade das sementes. Piracicaba: FEALQ, 1987. $230 p$.

MARTINS-CORDER, M. P. P.; MELO, I. S. Influência de Trichoderma viride e T. koningii na emergência de plântulas e no vigor de mudas de berinjela. Revista Brasileira de Biologia, v. 57, n.1, p. 39-45, 1997.

MACIEL, C. G. et al. Germinação e Sanidade de Sementes de Ipê-amarelo (Tabebuia serratifolia), após Submissão a Diferentes Tratamentos. Revista Brasileira de Agroecologia, v. 4, n. 2, p. 952-955, 2009. 
BARBIERI et all , v(11), no 11, p. 2413-2418, JUN, 2013.

Rev. Elet. em Gestão, Educação e Tecnologia Ambiental (e-ISSN: 2236-1170)

SCHUCH, L. O. B.; LIN, S. S. Efeito do envelhecimento rápido sobre o desempenho de sementes e de plantas de trigo. Pesquisa Agropecuária Brasileira, v. 17, n. 8, p. 1163-1170, 1982.

SCHUCH, L. O. B. Vigor das sementes e aspectos da fisiologia da produção em aveia-preta (Avena strigosa Schreb.), Pelotas: UFPel, 1999. 127p. Tese (Doutorado em Agronomia), Universidade Federal de Pelotas, 1999.

SCHUCH, L.O.B. et al. Crescimento em laboratório de plântulas de aveia-preta (Avena strigosa Schreb.) em função do vigor das sementes. Revista Brasileira de Sementes, v. 21, n. 1, p. 229-234, 1999.

SOAVE, J.; WETZEL, M. M. V. Patologia de sementes. Campinas: Fundação Cargill, 1987. 480p.

SOUZA, S. A.; NAKAGAWA, J.; MACHADO, C. G.Teste de envelhecimento acelerado em sementes de aveia preta.

Revista Brasileira de Sementes, v. 31, n. 2, p. 155-163, 2009. 